\title{
Stewardship of health security: the challenges of applying the One Health approach
}

Corresponding author:

Krishna Hort, Nossal Institute for Global Health, University of Melbourne, Australia Level 5, 333 Exhibition St, Melbourne, The University of Melbourne, Victoria 3000, Australia Phone 61247544352 Email: khort@unimelb.edu.au

Co-authors:

Angkana Sommanustweechai, International Health Policy Program, Ministry of Health, Thailand Wiku Adisasmito, Faculty of Public Health, University of Indonesia, Indonesia Laurence Gleeson, LJG Consulting, Australia

Acknowledgements

Dr Viroj Tangcharoensathien, Dr Waliporn Patcharanarumol, International Health Policy Program, Thailand for assistance in the Thai case study

\section{Summary}

Experience with the control of epidemics, notably the 2004 outbreaks of avian influenza, has demonstrated that a 'One Health approach', that recognizes that human, animal and environmental health are interdependent, is the most effective way of dealing with threats from emerging infectious diseases (EID). However, introducing and applying a One Health approach is challenging for many countries. One of the key challenges relates to stewardship.

The evolution of the strategies and policies used to introduce and adopt the One Health approach in the detection and response to EID over the period 2005 to 2017 is described at global level, and in country case studies of Thailand and Indonesia. Both countries

This is the author manuscript accepted for publication and has undergone full peer review but has not been through the copyediting, typesetting, pagination and proofreading process, which may lead to differences between this version and the Version of Record. Please cite this article as doi: $10.1002 /$ pad.1826

This article is protected by copyright. All rights reserved. 
experienced significant outbreaks of H5N1 avian influenza from 2004 and have sought to adopt the One Health approach in their response strategies.

The challenges for stewardship of health systems in introducing a One Health approach are described, and key lessons identified in regard to national level agency coordination, engagement of the broader civil society outside government, and developing a reliable, credible and impartial decision making process. The concept of stewardship provides valuable insights for policy makers on how to incorporate a One Health approach into their EID response systems.

Key words: Stewardship, One Health, Emerging Infectious Diseases, Thailand, Indonesia, 


\section{Introduction}

Emerging infectious diseases (EID) and the capacity of health systems to detect and respond to outbreaks of infectious disease have been recognized as a key challenge for health systems (Frieden et al, 2014). This has led to increasing interest in health security, and the responsibility of governments to 'protect the health and safety of its people', through the elements of prevention, early detection and timely and effective response (Frieden et al 2014).

Experience of the Ebola outbreak in West Africa in 2014-16 demonstrated the risks from the emergence of new infectious diseases that frequently arise from the interaction of humans, animals and the environment. Jacobsen et al (2016) in their review of the lessons from the Ebola outbreak identified the need to "increase zoonotic surveillance activities, implement more effective ecological health interventions, and to... support medical and public health systems to improve local and international responses to epidemics" (p. 200).

A One Health approach is increasingly considered to be the most effective way of managing and addressing EID threats (Degeling et al 2015, Vandersmissen and Welburn 2014). One Health is grounded in the recognition that human, animal and environmental health are interdependent, that animal species provide a shared reservoir for pathogen exchange and spread, and that many EIDs are driven by varied and dynamic human-animal interactions (Degeling et al 2015; Smith et al, 2010).

This article is protected by copyright. All rights reserved. 
However, implementing a One Health approach requires coordination and integration of programs and activities across three sectors - human health, animal health and the environment - which are traditionally managed separately by different government agencies. It also requires a decision making approach that extends beyond the traditional scientific, top down and technocratic approach, but incorporates the views and priorities of a range of social, economic and cultural interests (Degeling et al 2015). One Health requires national platforms that include key stakeholders, facilitate discussion, strengthen local leadership and ownership and enable a multidisciplinary culture (Vandersmissen and Welburn 2014). While currently One Health has mainly been applied to addressing threats related to EIDs, the concept that human health is inextricably linked to animal and environmental health and requires a collaborative response is relevant to addressing other health security challenges, such as those arising from natural disasters and chemical / biological and radiation incidents.

There are numerous barriers to the creation of systems that functionally integrate services that have traditionally been delivered by individual sectors with little or no collaboration or interaction between them. Some of them relate to budgetary constraints, unequal institutional capabilities and differing cultures, limited communication of information, the absence of a shared vision, and disincentives to working horizontally (Smith et al, 2010). As Degeling et al (2015) note, merely establishing mechanisms that enhance informationsharing, collaboration and inter-sectoral co-operation, such as working groups and interdepartmental committees, have rarely delivered the required outcomes. 
Introducing a concept such as One Health, developing the policy, regulatory and institutional basis, and the mechanisms and resources for its implementation involves the exercise of stewardship of the health system. Stewardship refers to the 'steering and regulation role of national stewards within health systems towards improved performance and related gains in health outcomes' (Barbazza and Tello, 2014, p 3). It combines the functions of leadership and oversight of governance, "ensuring that a strategic policy framework exists and is combined with effective oversight, coalition building, regulation, attention to system-design and accountability" (WHO 2014, p 10).

In this perspective, stewardship involves more than just formulating policy and strategic plans, but includes the functions of: transforming information into intelligence; putting in place levers and tools for implementing policy, including design of health system organisational structures and powers; building collaboration and coalitions across sectors; and ensuring accountability by putting in place appropriate governance structures, rules and processes (WHO 2014, p 10).

Stewardship is closely related to the concept of governance, which refers to the formal and informal 'rules that distribute authorities, roles and responsibilities among societal actors and shape the principal-agent interactions among them' (Brinkerhoff and Bossert, 2013, p 2). Stewardship is seen as providing the' overarching vision for the health system and establishing the boundaries in which the system's actors operate' (Barbazza \& Tello, 2014, p4). Thus stewardship includes oversight of the governance framework, but equally 
stewardship, particularly in regard to stewardship of one sector, operates within a governance framework, and needs to use that framework appropriately to achieve the desired goals. It is in this sense that stewardship and governance mutually interact.

Veillard et al (2011) in their review of the literature on the different definitions of stewardship, drew attention to the importance of the values of trust, ethical behaviour and sound decision making as underpinning good stewardship. They noted that stewardship expresses the "responsibility of government for the welfare of populations and ... the trust and legitimacy with which its activities are viewed by the general public" (Saltman and Ferroussier-Davis quoted in Veillard et al, 2011, p 192).

Characteristics of good stewardship identified by Veillard et al (2011, p 193) include:

- It takes place within an overall framework of agreed norms and values

- It is ethically driven, in turn implying an element of trust on behalf of the population

- It involves a focus on health system outcomes and on the well-being of the population

- It requires effective decision-making based on accountability and transparency, and

- it implies giving due attention to system design.

Effective exercise of the stewardship function is necessary to provide the policy guidance, institutional structure and values framework necessary to adopt and apply the One Health approach. However, the complex governance of health systems in low and middle income countries raises the question : how can governments in these countries exercise effective stewardship in introducing and implementing a One Health approach ?

This article is protected by copyright. All rights reserved. 
This paper describes and compares the introduction and adoption of the One Health approach to the surveillance and response to infectious disease in Thailand and Indonesia from the perspective of the stewardship function. Both countries experienced significant outbreaks of H5N1 avian influenza in 2004 and are at high risk for further outbreaks. Both countries have sought to adopt the One Health approach in building capacity to detect, control and respond to further outbreaks.

The paper will identify lessons for effective stewardship of the institutions and programs that address the issues of infectious disease prevention and control among humans and animals, and their interaction, with a focus on efforts to adopt and apply the One Health approach.

\section{Methods}

Case studies were undertaken of the policies and strategies that were introduced by the Governments of Thailand and Indonesia over the period following the outbreak of H5N1, from 2004 to the present. Case studies primarily used documentary sources (strategies, plans, regulations) produced by the respective governments, studies and research published in the literature, the in- depth understanding of the institutional context and operation of government of the two country authors (AS and WA), and the experience of the other two authors of the regional and global institutional context (KH and LG).

The case studies focused on the following questions:

This article is protected by copyright. All rights reserved. 
- What changes to government policy, regulations or institutions were introduced with the aim of combatting the outbreak of H5N1 and future emerging infectious disease?

- To what extent do these changes reflect and adopt the internationally recommended One Health approach?

- How were the strategies developed? What was the involvement of national and international experts in their development?

- What was basis of legitimacy or how was legitimacy built?

- What institutional arrangements were introduced?

- Were the policy and institutional arrangements, and the provision of resources, sharing of information, and ongoing responsibility for implementation, adequate to address the challenges of introducing a One Health approach?

- What has happened in terms of implementation / adoption since these policy and institutional changes?

The case studies were preceded by a review of the international and regional policy context, with a focus on policy and strategy recommendations and requirements from key global stakeholders, such as WHO, FAO and OIE, and regional level responses.

In assessing the challenges of introduce a One Health approach, we use the key elements of the collaboration between animal and human health identified in Smith et al, 2010 (p25):

- Shared surveillance to improve capability to detect emergence of disease events

This article is protected by copyright. All rights reserved. 
- Joint strategies for prevention and control, clearly defining roles, responsibilities and accountabilities

- Communicating consistent messages

- Joint preparation and testing of emergency preparedness plans and joint formulation of internal and external reporting and communication plans

- Sharing facilities and exchange of staff in surveillance and control operations to foster capacity

- New modalities for mobilizing financial resources

To this list we add two further important elements: (a) mechanisms to incorporate the principles and concepts of One Health into decision making on the priorities and strategies to address infectious diseases; and (b) an institutional arrangement that addresses the underlying policy and structural drivers of emergence or re-emergence of infectious diseases.

Our understanding of One Health was also informed by Vandersmissen and Welburn (2014): “Implementing One Health requires an appreciation of the links between human and animal health, ecosystems and the environment in general, as well as between livelihoods and policy processes. Gaining the full value of the One Health approach demands the support of and consultation with all sectors and industries that have a stake in health governance" ( $p$ 423).

Development of One Health and EID policy at Global, Regional and National levels

This article is protected by copyright. All rights reserved. 
Global governance of the response to EIDs is split among three organisations: World Health Organization (WHO) and Food and Agriculture Organization (FAO), both of which are UN organisations; and the World Organization for Animal Health (OIE), which is an intergovernmental organisation outside the UN. WHO's mandate and role was strengthened following the SARS outbreak in 2003, with the introduction of the International Health Regulations (IHR) as an international legal instrument binding on 196 countries, including all member states of the WHO. The IHR define the rights and obligations of countries to report public health events, and establish the procedures that WHO must follow in its work to uphold global public health security. (WHO 2017)

The concept of One World One Health to deal with emerging diseases at the human-animalecosystem interface formally emerged from a meeting convened by the Wildlife Conservation Society in 2004, at which the 12 Manhattan Principles concerning One Health were formulated. One Health subsequently became a prominent theme at the International Ministerial Conferences on Avian and Pandemic Influenza (IMCAPI) in New Delhi in 2007 and Sharm-el-Sheik in 2009.

Recognizing the need to ensure coordination between human health, animal health and agriculture, and to adopt the One health approach, WHO, FAO and OIE agreed on their respective roles and coordination mechanisms in a Tripartite Agreement in 2010 (FAO, OIE and WHO, 2010). This was followed, in 2014 , by the development of a joint WHO-OIE Operational Framework to support the integrated development of country capacities 
combining the WHO IHR monitoring framework with OIE's Performance of Veterinary Services Program framework.

The Operational Framework acknowledges and seeks to address the challenges of 'good governance at the human-animal interface' and the need to move from 'externally driven, short-term, emergency response type 'vertical' approaches, to a more sustainable, 'horizontal approach' and long-term strengthening of systems' (WHO, OIE, World Bank, 2014 p 6).

However, the establishment of the Global Health Security Agenda (GHSA) and more emphasis on health security, has led to the development of a more transparent and verifiable assessment of country capacity. The Joint External Evaluation (JEE) Alliance was formed in 2016 to support a country assessment process that involves both internal and external assessors, uses the IHR and OIE standards, and aims to improve linkage with national planning and implementation to follow up on the results of evaluations (JEE Alliance, 2017).

Meanwhile, although the One Health approach was enthusiastically adopted at a conceptual level, countries have had significant challenges in operationalising the One Health principles. A meeting of global experts and agencies held at Stone Mountain in the US in 2010 attempted to map out 7 key activity areas to drive the One Health agenda forward. One outcome of this and other similar meetings was the formation of the One Health Global Network (OHGN).

This article is protected by copyright. All rights reserved. 
Overall, a global framework on health security addressing EIDs and based on the One Health concept has progressively developed and resulted in an international regulatory environment and a growing body of technical expertise, with which there is broad, but variable engagement from national governments.

At a regional level, the countries of South East Asia have been recognized as a 'hot spot' for the emergence and re-emergence of infectious diseases at the animal -human interface (Coker RD et al, 2011). However, the regional response has mainly been in the form of technical support and capacity building. ASEAN has taken an active role, with pandemic preparedness and response identified as one of the four key strategic areas in the Strategic Framework on Health and Development $(2010-2015)\left(10^{\text {th }}\right.$ ASEAN Health Ministers Meeting, 2010). The regional WHO offices established the Asia Pacific Strategy for Emerging Diseases and Public Health Emergencies (APSED) and provide technical support and capacity building to Ministries of Health in countries in the SEARO and WPRO regions to achieve the IHR required capacities (WHO 2017b).

With the support of global donors, cross country and regional networks have been established to facilitate sharing of EID surveillance information. The Mekong Basin Disease Surveillance (MBDS) Network among Cambodia, China, Myanmar Thailand and Vietnam, was established in 2001 with support of the Rockefeller foundation (Phommasack et al 2013). Global support through networks such as the Connecting Organizations for Regional Disease Surveillance (CORDS), and the Centre for Disease Control (CDC) in the USA, have 
also contributed to linking national networks regionally and globally. FAO, OIE and WHO have established the Global Early Warning System (GLEWS) to pool information on health threats and emerging risks at the human-animal-ecosystems interface and then inform regional and national surveillance systems.

Donors also play an important role in One Health stewardship as they generally provide key financial inputs especially in resources poor countries, their interests span countries and even regions so their particular focus can provide an additional cohesion to programmes and they often play a key role in supporting international meetings and technical consultations. Donor support for the GHSA is a current example of the contribution to One Health stewardship.

These global and regional links have facilitated the introduction and adoption of the One Health Approach. For example, the Asia Partnership on Emerging Infectious Disease Research (APEIR), which began in 2006 with a focus on avian influenza research, now addresses a broader range of research across human and animal health in the countries of Cambodia, China, Indonesia, Lao PDR, Thailand and Vietnam,. The South East Asia One Health University Network (SEAOHUN) was established in 2011 as a network of universities in Malaysia, Indonesia, Thailand, and Vietnam to foster capacity building across disciplines in tackling emerging and re-emerging infectious disease challenges using a One Health approach. On the animal health side the ASEAN Agriculture Ministers formally endorsed the 
establishment of ACCAHZ (ASEAN Coordinating Centre for Animal Health and Zoonoses) in September 2016.

These and similar technical networks and collaborations have been regarded as 'critical alternatives to formalized institutional responses to outbreaks. This is especially true for issues of transnational concern where formal governance structures are inadequate' (Bond KC et al, 2013).

Overall, the global and regional institutional and policy environment has resulted in challenges for stewards of national health systems in terms of responding to and complying with international regulations, but has also contributed technical resources and capacity building support to guide them in their response. The country case studies will explore how two countries in the region have responded to their own national EID context, as well as to the global and regional institutional environment.

This article is protected by copyright. All rights reserved. 


\section{Case Study of Thailand}

\section{Introduction: evolution of responses to EID}

Although there had been increased awareness and action on EIDs in Thailand for decades, the identification in 2003 of a patient in Thailand with Severe Acute Respiratory Syndrome (SARS) acquired outside the country, triggered systematic policy actions by the Ministry of Public Health (MoPH) to strengthen preparedness and response to infectious disease with epidemic potential (Bureau of Epidemiology, 2003).

Thailand has faced a series of outbreaks and potential outbreaks of infectious disease since then, including Highly Pathogenic Avian Influenza H5N1 (HPAI H5N1), Chikungunya and most recently, local transmission of Zika virus in 2016-2017. Box one describes the chronology of EID in Thailand between 1999 and 2017.

Box 1: Chronology: EID outbreaks, Thailand, 1999-2017

- 2003: A case of SARS

- 2004-2008: HPAI H5N1 outbreak in humans and animals

- 2008-2009: Chikungunya outbreak in Southern region of Thailand

- 2009-2010: Pandemic H1N1 2009

- 2014-2016: Preparedness and response to West Africa Ebola epidemic outbreak

- 2015-2016: Three cases of Middle East Respiratory Syndrome (MERS CoV) acquired overseas

- 2016: Zika virus outbreak and local transmission

\section{Governance and institutional context}

This article is protected by copyright. All rights reserved. 
Multisectoral, multi-disciplinary and multi-level collaboration is required for successful EID responses. In Thailand, the MoPH, Ministry of Agriculture and Cooperatives (MoAC) and Ministry of Natural Resource and Environment (MNRE) are the key One Health partners that play significant roles in EID prevention and control. The MoPH Department of Disease Control is responsible for surveillance, detection and response to disease outbreaks in humans; while the Department of Livestock Development, MoAC is similarly responsible for animal health; collaboration between these two ministries is critical for the intersection between human and animal health. MNRE is responsible for monitoring, surveillance and outbreak containment in wildlife. Other institutions such as the Ministry of Interior, Ministry of Defence, the Provincial Office of Local Administration and civil society are also involved. The private sector, in particular the food and animal production sector, is indispensable in monitoring, reporting and containing zoonotic EID.

Thailand has a long history of devolving several legal authorities from national government agencies to the provincial level such as the Provincial Health Office representing the MoPH, the Provincial Livestock Office for the MoAC, and the Provincial Forestry Office for the MNRE. At the provincial level, there is also strong inter-sectoral collaboration through the convening power of the Provincial Governor. The provincial health offices are responsible for surveillance, prevention and response to EID at province level, through the network of provincial and district hospitals, and the surveillance network of sub-district health centres. The Provincial Livestock Office has its district and subdistrict offices for surveillance and responses. As mandated by the 2015 Communicable Disease Act, the Provincial 
Communicable Disease Committee chaired by the Governor is tasked to contain any infectious disease outbreak in the province based on a One Health approach.

In sum, the provincial, district and sub-district network of agencies, well established for decades, forms a solid backbone for EID surveillance and response.

\section{History and evolution of policy and strategies in response to EID}

Thailand adopted a "One Health" concept to consolidate and institutionalize a multi-sectoral coordination mechanism in response to EID threats. One Health principles were applied, though loosely, between animal and human health sectors, in addressing zoonotic diseases such as anthrax, rabies, and brucellosis even prior to the international concept formulation in 2004. For example, the 1955 Rabies Control Act mandates strong collaboration between the two health sectors.

The first human case of HPAI H5N1 was announced in January 2004. The mass media coverage of its $60 \%$ case fatality rate, its rapid spread to several provinces and the lack of an effective human vaccine heightened public concern, and led to panic and dissatisfaction. The Prime Minister, through executive order, established a national committee chaired by the Deputy Prime Minister, with membership of six ministers and a representative of the National Economic and Social Development Board. The committee led the successful multisectoral response which resulted in control of the outbreak. Recognizing the need to establish more effective ongoing control mechanisms, the Deputy Prime Minister convened a group of experts from government ministries and academic institutions to develop for first 
National Strategic Plan for Preparedness and Response to Avian Influenza and Pandemic Influenza (2005-2007). A second plan was developed for the period 2008-2010 which was also focused on avian influenza and pandemic preparedness. Both plans emphasized cross sectoral cooperation and international collaboration (Sommanustweechai et al 2017).

These plans successfully mobilized resources and established surveillance and response mechanisms in both sectors. The MoPH established Surveillance and Rapid Response Teams (SRRT) at the national, provincial and district levels. By 2017, there were 946 district and 9,882 sub-district SRRT teams (Bureau of EID, 2013) which coordinate disease surveillance and investigation, effective responses and collaborate closely with local government. In addition, the lack of seasonal influenza vaccine production capacity in Thailand prompted the government to invest, through a Cabinet Resolution, in the establishment of seasonal influenza vaccine production plant managed by the Government Pharmaceutical Organization. Thailand has been largely successful in reducing the risk of avian influenza, with the last poultry outbreak reported in November 2008, and the last human case in July 2006 (Bureau of EID, 2013).

While these plans focused on avian influenza and pandemic influenza, there was increasing recognition of the need for a broader scope based on the One Health approach. Ongoing experience with the interaction of human and animal health, such as the emergence of leptospirosis in 2009, fostered the establishment of the Thailand One Health Network and the One Health Declaration in 2011. This network brought together government officials, 
researchers, academics and experts from international development partners. It formed a horizontal thread which enhanced the vertical threads of bureaucratic systems (Thai One Health Network, 2011). The Thailand One Health University Network (THOHUN) was established as part of South-East Asia One Health University Network, to develop the curriculum for post-graduate capacity building for human, animal and environment sectors (Thai One Health University Network, 2013). International developments also influenced Thailand's policy development, particularly through the hosting of the Second International One Health Congress in Bangkok as the Prince Mahidol Award Conference in 2013. (Sommanustweechai et al 2017)

The Bureau of Influenza established in the MoPH in 2005 functioned as the technical secretariat for the National Committee in development of the Strategic Plans of 2005-07 and 2008-10. In 2008 it was transformed into the Bureau of Emerging Infectious Disease (BoEID), reflecting a broadening in scope. At the same time, in 2009, the National Health Assembly, a policy consultative body with government, academic and general public members, adopted a resolution requesting the development of a strategic plan for more effective EID management. As a result, the MoPH convened a committee with representation from a range of ministries, academia and civil society to develop a National Strategy that addressed EIDs more broadly. The National Strategic Plan for Emerging Infectious Disease (2013-16) incorporates the One Health concept and stresses the participation of all sectors including the government, private sector and community (Sommanustweechai et al 2017).

This article is protected by copyright. All rights reserved. 
To ensure continuity in containing EID across successive governments, the national committee is a standing committee, appointed by the Prime Minister, chaired by the deputy prime minister, with membership ex-officio of ministers and permanent secretaries from various ministries, private sector, and six experts in their personal capacities. The committee is supported by a joint secretariat of four Directors-General, from the Department of Disease Control (DDC), Department of Livestock Development (DLD), Department of Disaster Prevention and Mitigation (DDPM), and Department of National Parks, Wildlife and Plant Conservation (DNP) (Bureau of EID, 2016). These four EID implementing agencies are the definitive stakeholders in ensuring success of EID containment.

The National Health Assembly continued to play a role in stimulating policy development, passing a resolution in 2013 to apply the One Health concept at community level in tandem with the National Strategic Plan for EID (National Health Assembly, 2014). This enhanced public awareness and widened recognition to non-governmental agencies, civil society and local people through an extensive period of consultation and active participation at all levels. This resolution played an indirect role in fostering recognition of One Health and EID, as it came after the EID plan (2013-2016) was developed (Rasanathan et al 2012). Progress on implementation was reported in 2015 to the Assembly as mandated by the Resolution.

In 2016, an inter-ministerial MOU between MoPH, MoAC, MRNE and THOHUN supporting the One Health concept provided a firm and sustainable foundation for multisectoral collaboration, which will support the implementation of the next National Strategic Plan for 
EID (2017-2021). This plan proposes six inter-linked synergistic strategies, focusing on multisectoral collaboration on public health emergency response, surveillance, prevention and treatment of EIDs under the One Health concept; risk communications and public awareness campaign relating to EID; improved international collaboration, engagement and participation from civil society and the private sector for EID prevention and control; and improved knowledge management supporting research and development.

While no dedicated national budget allocation was made to the One Health program, individual national agencies allocated funds from their own budgets. International development partners including FAO, WHO, USAID and US CDC also made significantly contributions, both technical and financial, to promoting multi-sectoral and multidisciplinary collaboration.

\section{Adequacy of stewardship in introducing and operationalizing One Health}

Stewardship in Thailand has focused on developing a shared vision, mutual respect and trust across stakeholder agencies as important ingredients for successful collaboration. An important element of the approach to stewardship has been the use of multiple mechanisms that complement each other, and enable engagement of the full range of stakeholders. These include the formal national level committee bringing together government office holders; networks, and relationships between technocrats both within government and outside government; the engagement of civil society through the National 
Health Assembly; and the development of district, sub-district and village level networks that engage the community.

Implementing these strategies has built on long term collegial relationships among cross sectoral technical experts. These relationships are more stable than those among high-level policy makers where there is frequent turnover in position holders. Effective collaboration among technical experts is more sustainable.

Development of effective engagement with communities is another key element of the Thai approach to stewardship. The Surveillance and Rapid Response Teams (SRRT) are the backbone for integrated services, including disease surveillance and responses. Village health volunteers report via mobile phone of outbreak events in humans and animals (including human infections linked to contact with animals and animal products) in their communities for further verification by SRRT, as well as facilitate public communication to prevent social disruption and panic during any epidemic or pandemic events.

This approach can be seen in the progressive evolution of the policy agenda, from a focus on avian influenza, to the adoption of the One Health concept, and broadening of scope to encompass the range of EIDs. The Thai approach has achieved some notable success, which has been confirmed by the recent JEE report (June 2017) which found that Thailand fully satisfied the criteria for 11 categories, partially for 5, and in only three categories did not satisfy all indicators (WHO 2017c).

This article is protected by copyright. All rights reserved. 
On the animal health side of the One Health agenda the role of strong private sector stakeholders was very important to the Thai government engagement with HPAI control. The value of the chicken export industry that was lost during the outbreak provided a strong incentive for the Agriculture Ministry and the private sector to cooperate to enable restoration of export approval. In this case, the impact of animal disease on both the national economy and the public health risk contributed to strengthening stewardship and engaging the private sector. However, this engagement will not necessarily remove incentives to under-report if the ethics and priorities of the business community are not aligned with those of the other stakeholders.

In conclusion, stewardship in Thailand has progressively built a constituency that shares the vision and values of One Health, and has enabled engagement of a range of stakeholders through a variety of mechanisms. It has had some success in building implementation capacity, but is oriented towards outbreak control and responses and has yet to scale up efforts to contain disease at the origin. For example, wide coverage of vaccines for eliminating rabies through the global framework of rabies elimination has yet to scale up (Food and Agriculture Organization et al, 2017). Cross-sectoral policy has yet to address the underlying conditions, such as changes in land use, agricultural intensification and deforestation, which result in exposure of humans to emerging pathogens,. In addition, antimicrobial resistance (including MDR TB) are among the major EID threats that warrant greater policy attention.

This article is protected by copyright. All rights reserved. 


\section{Case Study of Indonesia}

Indonesia faces a number of challenges with emerging infectious diseases, particularly those of zoonotic origin. The H5N1 avian influenza outbreak from 2003 resulted in 197 human cases in Indonesia with 167 deaths), spread over 15 provinces. While the last human cases were reported in 2015 , outbreaks continue to occur in poultry, and there continues to be a high risk of transfer to humans. Other zoonotic diseases of concern in Indonesia include the incursion of rabies on Bali and ongoing endemic disease in 25 provinces, and sporadic cases of leptospirosis and anthrax (Ministry of Health, Republic of Indonesia 2016 p 197).

\section{Institutional and governance context}

Indonesia has a decentralized system of government with responsibilities, roles and functions for human and animal health divided among the three tiers of government: central, provincial and district. According to Law 23/2014, responsibility for the detection and response to outbreaks of infectious disease is a concurrent responsibility divided between central and local governments, with each level of government responsible for the management and control of outbreaks at their level. However, Law 41 of 2014 on Livestock and Animal Health, states that animal health is a priority responsibility for local government, resulting in some lack of clarity on the relationship among the levels of government for animal health matters.

Responsibilities for human and animal health are also divided between two ministries, and similar human and animal health government agencies at provincial and district level that 
report to their respective levels of government. The Ministry of Health, through the Directorate-General for Disease Control and Prevention (DGDCP), is responsible for surveillance, detection and response to outbreaks of infectious disease among humans. The Ministry of Agriculture, through the Directorate-General for Livestock and Animal Health Services (DGLAHS) is responsible for similar functions in relation to animal health. Other institutions involved include the Coordinating Ministry for Human Development and Cultural Affairs (CMHDC) and the National Agency for Disaster Management.

\section{Policy and institutional arrangements introduced to respond to the outbreak of H5N1 avian influenza and zoonotic emerging infections and their evolution 2006 - 2016.}

In response to the spread of H5N1 avian influenza, the President issued an instruction to establish the National Commission for Avian Influenza Control and Pandemic Preparedness (Komnas FBPI) in March 2006. This was a ministerial level committee led by the Coordinating Minister for Social Welfare, and was charged with developing policy and coordinating responses. The committee developed a National Pandemic Preparedness and Response Plan in 2007, and activated this plan in 2009 when WHO declared a pandemic alert for H1N1 influenza in 2009. The committee established a secretariat, various working groups, and similar committees at provincial and district levels. While Komnas FBPI was able to develop strategic plans, it lacked direct access and authority to implement plans, as this was held by the relevant ministries. The experience of the 2009 response to H1N1 influenza demonstrated that human resource inadequacies, inflexible bureaucracy and regulatory 
complexity inhibited release of funds and constrained the effectiveness of the response (Adisasmito et al, 2014).

Komnas FBPI was replaced by the National Commission for Zoonosis Control (Komnas PZ) in 2012 by presidential regulation 30/2011. This presidential regulation provided a stronger regulatory basis for the operation of the Komnas $\mathrm{PZ}$, broadened its scope from avian influenza to zoonoses and nominated eight strategies for zoonosis control. The Komnas PZ was otherwise similar in structure to the Komnas FBPI, with a ministerial committee led by the Coordinating Minister, and with roles of functional coordination, as well as operational command in the event of an outbreak or epidemic. A group of human and animal health sector experts from several universities and academic institutions across Indonesia provided technical support to the Komnas. Like the Komnas FBPI it reported directly to the President. The concept of One Health had become internationally recognized by this stage, and an organisation of academics, practitioners and government technocrats was established in 2012 with the title INDOHUN (Indonesia One Health University Network). INDOHUN worked to build collaboration among its members through the development of training programs, and holding of workshops, as well as providing expert advice to government. By 2017, INDOHUN had conducted 9 pre-service and 6 in-service training programs, covering more than 260 academics, and 500 students, and around 1000 other participants (Personal communication, Adisasmito, 2017).

This article is protected by copyright. All rights reserved. 
One of the first actions of the Komnas PZ was to develop a National Strategic Plan for the Integrated Control of Zoonosis 2012-17. The national strategy referred to the Manhattan principles on One World One Health, and focused on the need for a multi-sectoral and integrated approach, prioritizing human safety, while considering the economic, social, political, cultural and security factors (National Committee for Zoonosis Control, 2012).

Following development of the national strategy, efforts focused on its implementation, including seeking a regulation from the Coordinating Ministry on the administrative arrangements for coordination; issuing a directive that would require local governments to take responsibility for infectious disease surveillance and control; and developing more detailed coordination procedures (National Committee for Zoonosis Control, 2013).

The regulation establishing the Komnas PZ stipulated a five-year lifespan, to end in 2017, and led to a search for an ongoing institutional coordination mechanism. The CMHDC engaged INDOHUN to develop a white paper and policy brief evaluating the role of Komnas PZ, which proposed that its role and function be transferred to the CMHDC. This was then enacted by the President in December 2016, through Presidential Regulation No 116/2016 which dissolved the Komnas PZ and transferred its functions to the CMHDC.

The process of transfer of function is currently under way, and will be completed by the end of 2017. The Assistant Deputy for Prevention and Control of Disease within the CMHDC now has responsibility for coordination of the national program, and has prioritized the preparation of coordination guidelines for response to an outbreak or epidemic. He notes 
the need for close connection between human health, animal health and the environment as 'One Health' (CMHDC, 2017). The draft coordination guidelines were released in February 2017. INDOHUN continues to support the CMHDC in its new role through an expert panel constituted by experts from the 34 medicine, veterinary medicine and public health facilities that are members of INDOHUN.

Issues with current arrangements: The Ministry of Agriculture is not under the coordination authority of CMHDC, although the Ministry of Health is. Confusion on the responsibilities of local government for animal health, resulting from the inconsistencies between the two laws, and the much lower level of resources and capacity in the animal health sector, also hampers coordination between human and animal health. Meanwhile each ministry continues to maintain separate surveillance systems, which are yet to be linked.

The extent of interest, priority and support for detection and response to EIDs varies among local governments, resulting in variation in levels of capacity among provinces and districts, and between animal health and human health. While the establishment of veterinary authorities at national, provincial and district level will provide the veterinary office with increased authority, animal health resources and capacity remain much less than human health, and the priority of animal health is more on maintaining livestock production, than on mitigating risk to human health.

There are also issues with access to resources at provincial and district levels in the event of an outbreak. Funding for 'non-natural' disasters, which include disease outbreaks, is 
available through the National Disaster Management Agency, and its subnational representatives. However, access to these funds requires local government approval, while the Standard Operating Procedures (SOPS) to support this process are still under development.

\section{Adequacy of stewardship in introducing and operationalizing One Health}

The Indonesian government has been active in stewardship in terms of setting national priorities, developing national strategies, and national level institutional and policy structures. While direct reference to One Health is not frequent, the underlying concept is reflected in the efforts towards coordination and integration. International and regional policy has played a role in encouraging Indonesia and is referred to in the national strategy. More recently Indonesia's membership of the Global Health Security Agenda (GHSA) has given new impetus towards efforts at zoonosis control. Indonesia is proposing to undergo the JEE assessment later this year (2017).

The scope of policy and strategy has broadened from the initial focus on avian influenza to zoonoses, but has yet to address the broader questions of emerging infectious disease (EID), although the Ministry of Health has recently established a Directorate of EID under the DGDCP. However, agricultural policy and priorities within the MoA have not yet engaged with the need to invest in One Health to achieve human health outcomes, but rather continue to focus on livestock production and food security outcomes. It is also recognised 
that the animal health sector is a relatively small and politically weak entity within the large Agriculture Ministry.

Overall, stewardship of One Health has struggled with the constraints and confusions in the overall institutional governance arrangements. As a result, stewardship in terms of setting priorities and directions has been active, but stewardship in terms of operationalizing these priorities and directions, and enabling implementation, has struggled. This is reflected in the disparities between $\mathrm{MoA}$ and $\mathrm{MoH}$ priorities, ongoing difficulties in getting lower levels of government to prioritize zoonosis control, and the continuing search for mechanisms to support operational coordination such as SoPs. Where MoA and $\mathrm{MoH}$ have a conjunction of interest, such as in dealing with antimicrobial resistance, there is more institutional engagement. However, several subnational level governments have been able to effectively operationalize coordinated responses to localized outbreaks, particularly the more efficient and well resourced local governments. Examples include responses to Anthrax in Yogyakarta, and Rabies in Bali where the Integrated Bite Case Management generated effective cross-sectoral coordination. In addition, USAID supports a One Health capacity building project in a limited number of pilot districts, and the implementation of training outputs in case studies has demonstrated the utility of the approach to local decision makers. In early 2018 in association with national counterpart agencies, FAO, OIE and WHO will trial a new EIDs joint risk assessment tool in Indonesia.

\section{Discussion}

This article is protected by copyright. All rights reserved. 
Introducing a One Health approach to programs to detect and respond to emerging and reemerging infectious disease creates challenges for stewardship. The case studies demonstrate how two countries that have adopted a One Health approach and invested significantly in preparedness for EID have exercised stewardship in responding to the global and regional context, and their own national challenges.

The initial challenge is to establish a national level institutional arrangement that enables coordination across key ministries, particularly human health and animal health; provides national level authority; and addresses international responsibilities and expectations, while demonstrating the government's capacity to protect the public from EID. National ministries tend to function as hierarchical vertical institutions, so that coordinating and gaining collaboration across ministries was a challenge in Indonesia and Thailand. Both country governments established separate coordinating institutional structures in the form of national commissions that report to the highest level of government and provide a platform for strong stewardship at a national level, as well as ready access to the highest levels of government.

However, from a governance perspective, national commissions are an additional institutional mechanism that is specific to a particular issue, and can lead to a multiplicity of commissions, as has occurred in Indonesia. Indonesia has attempted to rationalize the use of national commissions by limiting their life span, and has introduced coordinating ministries in an effort to address the horizontal coordination across Ministries. Coordinating 
ministries do bring a stable institutional framework, which can be effective - but in the case of One Health, the MoA is under a different Coordinating Ministry than the MoH, thus undermining the potential benefits of the coordinating function. This is an interesting example of the inter-relationship of stewardship and governance, where stewardship of One Health requires finding ways to operate in a complex and sometimes confusing governance environment.

The evolution of national strategies in both countries demonstrate a progressive adoption of One Health concepts, and a broadening of scope from a focus on avian influenza, to a broader focus on zoonoses and EID. This appears most likely to be in response to changes in the global and regional agenda and guidance and direction from WHO, UN agencies and development partners. This suggests that global stewardship of EID has been reasonably effective. Global stewardship has used a combination of formal, legal mechanisms, such as the IHR and the JEE, that primarily engage political and bureaucratic leaders; as well as informal engagement of technocrats through global technical networks. It is also likely that the democratic systems in both countries, and the need for government to demonstrate leadership in protecting the public, have also encouraged progress on this policy agenda.

The second challenge is to operationalize One Health and establish coordination at subnational level (province / district / subdistrict). Both countries have decentralized to some degree, thereby reducing the authority of central level to direct the subnational level. This encourages subnational governments to take a role in coordination, but risks disrupting 
the vertical lines of information flow and control of implementation. Indonesia has tried various methods to engage local governments and ensure that EID and One Health approaches are a local priority. However, considerable disparities in the level of resources and capacity among local governments has further complicated development of an integrated national program. Thailand appears to have developed better local level coordination than Indonesia, perhaps due to its longer history of functioning local health networks.

The third challenge is to extend beyond government to engage with the private sector, civil society, professions and others involved in a One Health approach. This is important not only for the implementation of a One Health approach, but is also needed to address the underlying determinants of EIDs. While both countries consulted with technical experts during the preparation of strategic plans, and technical networks were formed, the process in Indonesia appears to have been strongly government centred. While in Thailand, the active networks among academics, professions and technical experts, and the active engagement of the National Health Assembly, suggest that the stewardship process operated across both government and outside government. This multi- strand strategy provides an opportunity for broader support for implementation, and demonstrates a more inclusive and open decision-making process.

This observation leads to the fourth challenge which relates to establishing a process and basis for decision making that is seen as credible, legitimate and trusted by the general 
public and stakeholders. In the event of an outbreak, decisions will need to balance public welfare against the commercial interests and livelihoods of livestock owners. This will require decision making that is seen to be transparent, free from influence from political or special interest groups, and based on evidence, data, and expert advice. It will also require mechanisms to hold decision makers accountable for their decisions. This is an aspect of the stewardship of One Health that has been rather neglected, both in the global and regional guidance, and also in both of the case study countries. However, clarity on decision making mechanisms and their basis will be necessary to address the more difficult issues of prevention and the contesting interests around land use, livestock production, and other issues such as the use of antimicrobials. Neither country has made much progress on this aspect.

The case studies identify the importance and relevance of stewardship, and show that effective stewardship extends beyond national level coordination and production of national strategic plans. The studies also demonstrate the interaction of stewardship and governance as stewardship establishes new institutional mechanisms for coordinated decision making within the governance structure of decentralisation and vertical line ministries.

The following lessons emerge from the analysis:

(1) Importance of the regional and global policy framework and role of international organisations and development partners. These institutions exercise stewardship at a global 
and regional level through a combination of formal and informal means. This stewardship greatly influences national strategies and policy making. Mechanisms that enable greater engagement of countries themselves, and greater transparency in global and regional decision making can model good stewardship and ensure decisions better reflect national conditions.

(2) National-level stewardship is more effective when combining formal government channels, and informal channels addressing technical experts, academics and providers. In the complex governance environments of competing sectoral interests, and devolution of authority to lower levels of government, use of multiple mechanisms for stewardship is likely to be more effective than relying on government channels alone.

(3) Developing effective mechanisms for coordinated and responsive decision making at subnational level remains a challenge, particularly in decentralized environments. It appears to be more effective when built on longer term and ongoing collective action (as in Thailand), rather than ad hoc or special purpose arrangements.

(4) It is important to provide robust structures and mechanisms for impartial decision making that are transparent, accountable, and explicit on the values and basis for decisions. This will support public confidence in responses to outbreaks, and also assist in addressing the more contested underlying determinants of EIDs.

\section{Conclusions}

This article is protected by copyright. All rights reserved. 
The introduction and adoption of One Health in health system responses to EIDs requires an exercise of stewardship at multiple levels - global, regional, national and sub-national. A broader understanding of the concept of stewardship and how it can be applied could improve the processes and mechanisms needed to develop and deliver programs that can apply a One Health approach to addressing EIDs. As application of the One Health approach extends to address more complex underlying issues, such as antimicrobial resistance, and environmental change, stewardship will need to address the challenge of expanded coordination to include wildlife and environmental sectors.

In particular, this comparative study demonstrates that stewardship involves more than just developing national policy and strategies., It extends to establishing the structures, processes and basis for further decision making at national and subnational levels; and beyond government channels, to engage with and involve non-government technical experts, the private sector, civil society and the community.

This article is protected by copyright. All rights reserved. 
References

Adisasmito W, Suwandono A, Aisyah DW (2014). Measuring Indonesia H1N1 Pandemic preparedness through stakeholder analysis. Health Care Current Reviews 2:1 /dx.doi.org/10.4172/hccr.1000119

Barbazza E, Tello J.E (2014). A review of health governance: definitions, dimensions and tools to govern. Health Policy 116:1- dx.doi.org/10.1016/j.healthpol.2014.01.007

Bond KC, Macfarlane SB, Burke C, Ungchusak K, Wibulpolprasert S (2013). The evolution and expansion of regional disease surveillance networks and their role in mitigating the threat of infectious disease outbreaks. Emerg Health Threats ; 6: 19913 http://dx.doi.org/10.3402/ehtj.v6i0.19913

Brinkerhoff DW, Bossert TJ. (2013). Health governance: principal-agent linkages and health system strengthening. HIth Pol \& Planning 6:685-93 doi:10.1093/heapol/czs132

Bureau of Epidemiology, Department of disease control, Ministry of Public Health (2003). Annual Epidemiological Surveillance Report 2003 ISSN 0857-6521.. Available from: www.boe.moph.go.th/Annual/Annual\%202546/Part1/29SARS.doc [cited 15 September, 2017]

Bureau of Emerging Infectious Disease, Department of disease control, Ministry of Public Health (2013). The National Strategic Plan for Preparedness and Response to EID in Thailand (2013-2016).. Available from: 
http://beid.ddc.moph.go.th/th 2011/upload/eidnationplan56 59.pdf [cited 15 September, 2017]

Bureau of Emerging Infectious Disease, Department of disease control, Ministry of Public Health (2016). The National Strategic Plan on EID (2017-2021). Available at http://beid.ddc.moph.go.th/beid 2014/sites/default/files/eidnationplan60 64.pdf [accessed 29 September 2017]

Coker RD, Hunter BM Rudge JW, Liverani M et al.(2011) Emerging infectious disease in southeast Asia: regional challenges to control. Lancet 377, 9765:599-609 http://dx.doi.org/10.1016/S0140-6736(10)62004-1)

Coordinating Ministry of Human Development and Culture, 2017. Follow up to the disbanding of the National Commission for Zoonosis Control. Press release, March 2017. Available at https://www.kemenkopmk.go.id/pengumuman/tindak-lanjut-pembubarankomisi-nasional-pengendalian-zoonosis (accessed 3 August 2017)

Cork SC, Geale DW, Hall DC. One health in policy development: an integrated approach. Chapter 25 in Zinsstag et al , 2015

Degeling C, Johnson J, Kerridge I, Wilson A, Ward M, Stewart C, Gilber G. Implementing a One Health approach to emerging infectious disease: reflections on the socio political, ethical and legal dimensions. BMC Public HIth 2015 15:1307 DOI 10.1186/s12889-015-26171

This article is protected by copyright. All rights reserved. 
FAO, OIE, WHO (2010). The FAO-OIE-WHO Collaboration, A tripartite Concept Note. $\begin{array}{lll}\text { Accessed } & \text { from: } & \text { http://www.who.int/ihr/publications/WHO- }\end{array}$ OIE Operational Framework/en/ Accessed on 29 September 2017

FAO, Global Alliance of Rabies Control, WHO, OIE. Global framework for the elimination of dog-mediated human rabies. [cited 15 September, 2017]. Available from: http://www.oie.int/fileadmin/Home/eng/Media Center/docs/pdf/Rabies portal/EN Timeis nowGlobalFramework.pdf) .

Frieden TR, Tappero JW, Dowel SF, Hien NT, Guillaume FD, Aceng JR. (2014). Safer countries through global health security. Lancet 383: 764-766 dx.doi.org/10.1016/S01406736(14)60189-6

Jacobsen KH, Aguirre AA, Bailey CL, Varanova AV, Crooks AT, Croitoru A, Delameter PL et al. (2016) Lessons from the Ebola outbreak: action items for emerging infectious disease preparedness and response. Eco Health 13:200-212 DOI 10.1007/s10393-016-1100-5

JEE Alliance (2017). About the JEE Alliance. Available from www.jeealliance.org/about/ (accessed 29 September 2017)

Ministry of Health, Republic of Indonesia (2016), Health Profile Indonesia Year 2015. $\begin{array}{lllll}\text { Kementerian } & \text { Kesehatan } & \text { RI } & \text { Jakailable } & \text { from }\end{array}$ http://www.depkes.go.id/resources/download/pusdatin/profil-kesehatan-indonesia/profilkesehatan-Indonesia-2015.pdf (Accessed 21 March 2017) 
National Health Assembly (2014) The Sixth National Health Assembly Agenda Agenda 2.7 Multi-sectoral Collaboration for "One Health" of Humans, Animals and Environment. [cited 15 September, 2017].

Available from:

http://nha2013.samatcha.org/sites/default/files/NHA6 res6 7 one health.pdf [accessed May 1, 2015]

National Committee for Zoonosis Control (2012). National strategic plan for the integrated control of Zoonosis 2012-2017 [Rencana nasional strategis pengendalian zoonosis terpadu]. Available from

https://xa.yimg.com/kq/groups/23509172/1018204139/name/renstra+P+ZOONOSIS+TERPA DU+knpz.pdf . (accessed 3 August 2017)

National Committee for Zoonosis Control (2013). National Report for Year 2012. [Laporan $\begin{array}{llll}\text { Nasional } & \text { Tahun } & \text { 2012]. } & \text { Available }\end{array}$ https://www.k4health.org/sites/default/files/laporan\%20nasional\%20KNPZ\%202012 0.pdf (Accessed 3 August 2017)

Phommasack, B., Jiraphongsa, C., Ko Oo, M., Bond, K. C., Phaholyothin, N., Suphanchaimat, R., Ungchusak, K., Macfarlane, S. B. (2013). Mekong Basin Disease Surveillance (MBDS): A Trust-Based Network. Emerging Health Threats Journal, 6, 10.3402/ehtj.v6i0.19944. http://doi.org/10.3402/ehtj.v6i0.19944

This article is protected by copyright. All rights reserved. 
Rasanathan K., Posayanonda T., Birmingham M., and Tangcharoensathien V (2012). Innovation and participation for healthy public policy: the first National Health Assembly in Thailand. Health Expectations ;1:87-96. doi: 10.1111/j.1369-7625.2010.00656.x

Smith JW, de Hann C, Larson G, Robles S, Sperling U. (2010) People, Pathogens and Our Planet. Vol 1: towards a One Health approach for controlling zoonotic diseases. World Bank Report 50833-GLB http://siteresources.worldbank.org/INTARD/Resources/PPP Web.pdf (Accessed 3 May 2017)

Sommanustweechai A, lamsirithaworn S, Patcharanarumol W, Kalpravidh W, Tangcharoensathien V (2017). Adoption of One Health in Thailand's national strategic plan for emerging infectious diseases. Journal Public Health Policy 38: 121-136 doi:10.1057/s41271-016-0053-9

$10^{\text {th }}$ ASEAN Health Ministers Meeting (2010). Joint Statement. Available from http://asean.org/?static post=joint-statement-of-the-10th-asean-health-ministers (accessed 29 September 2017)

Thai One Health Network (2011) Declaration of Intention on One Health Thailand. Available from: http://www.thaionehealth.org/contents/view/197 (Accessed 15 September 2017)

Thailand One Health University Network (2013) THOHUN Newsletter Vol.1, December 2013. Available from: : http://thohun.org/publication/ (Accessed 15 September 2017)

This article is protected by copyright. All rights reserved. 
WHO (2014) Health systems governance for universal health coverage. Department of Health Systems Governance and Financing. Action Plan. WHO, Geneva. Available at http://www.who.int/universal health coverage/plan action-hsgov uhc.pdf (accessed 2 September 2016)

WHO (2017a). International Health Regulations (IHR). Available from : http://www.who.int/ihr/about/en/ ( accessed on 29 September 2017)

WHO (2017b). Asia Pacific Strategy for Emerging Diseases and Public Health Emergencies (APSED III). WHO Regional Office for the Western Pacific, Manila Philippines. Available at: http://iris.wpro.who.int/bitstream/handle/10665.1/13654/9789290618171-eng.pdf (accessed 3 October 2017)

WHO (2017c). Joint external evaluation of the IHR core capacities of the Kingdom of Thailand. Executive Summary, June 2017. (WHO/WHE/CPI/SUM/2017.38). Available from: www.who.int/ihr/publications/WHO-WHE-CPI-SUM-2017.38/en/ (accessed 30 September 2017)

WHO, OIE, World Bank (2014). WHO-OIE Operational Framework for good governance at the human-animal interface. Available from : http://www.who.int/ihr/publications/WHOOIE Operational Framework.pdf (accessed on 3 October 2017)

Vandersmissen A, Welburn S.C (2014). Current initiatives in One Health: consolidating the One Health Global Network. Rev Sci Tech Off Int Epiz. 33 (2) 421-432

This article is protected by copyright. All rights reserved. 
Veillard, JHM, Brown, AD, Baris E, Permanand G, Klazinga NK.(2011). Health system stewardship of National health ministries in the WHO European region: concepts, functions and assessment framework. Health 103:191-99 dx.doi.org/10.1016/j.healthpol.2011.09.002

Zinsstag J, Schelling E, Waltner-Toews D, Whittaker M, Tanner M (Eds) One Health (2015). The Theory and Practice of Integrated Health Approaches. CAB International, Oxford, UK. 
Title Page

Stewardship of health security: the challenges of applying the One Health approach

Corresponding author:

Krishna Hort, Nossal Institute for Global Health, University of Melbourne, Australia

Level 5, 333 Exhibition St, Melbourne, The University of Melbourne, Victoria 3000, Australia

Phone 61247544352 Email: khort@unimelb.edu.au

Co-authors:

Angkana Sommanustweechai, International Health Policy Program, Ministry of Health, Thailand

Wiku Adisasmito, Faculty of Public Health, University of Indonesia, Indonesia

Laurence Gleeson, LJG Consulting, Australia

Acknowledgements

Dr Viroj Tangcharoensathien, Dr Waliporn Patcharanarumol, International Health Policy Program, Thailand for assistance in the Thai case study

This article is protected by copyright. All rights reserved. 


\section{University Library}

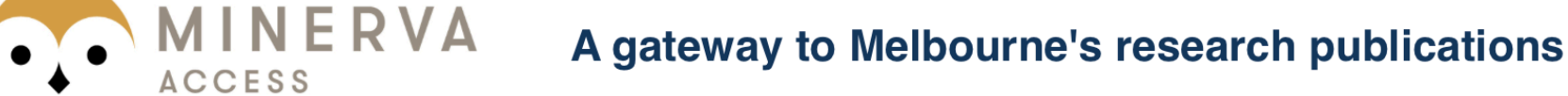

Minerva Access is the Institutional Repository of The University of Melbourne

Author/s:

Hort, K;Sommanustweechai, A;Adisasmito, W;Gleeson, L

Title:

Stewardship of health security: The challenges of applying the One Health approach

Date:

2019-02-01

Citation:

Hort, K., Sommanustweechai, A., Adisasmito, W. \& Gleeson, L. (2019). Stewardship of health security: The challenges of applying the One Health approach. PUBLIC ADMINISTRATION AND DEVELOPMENT, 39 (1), pp.23-33. https://doi.org/10.1002/ pad. 1826.

Persistent Link:

http://hdl.handle.net/11343/284017 